\title{
METÁSTASIS GÁSTRICA DE UN ADENOCARCINOMA RENAL. HIPÓTESIS PATOGÉNICA Y REVISIÓN DE LA LITERATURA
}

\author{
C. SUÁREZ FONSECA, J. CARBALLIDO RODRÍGUEZ, Y. GONZÁLEZ LAMA*, \\ I. SOLA GALARZA, G. RODRÍGUEZ REINA, C. SALAS ANTÓN** \\ Servicios de Urología, *Gastroenterología y **Anatomía Patológica. \\ Hospital Universitario Puerta de Hierro. Madrid. \\ Actas Urol Esp. 28 (6): 472-476, 2004
}

\section{RESUMEN}

\section{METÁSTASIS GÁSTRICA DE UN ADENOCARCINOMA RENAL. HIPÓTESIS PATOGÉNICA Y REVISIÓN DE LA LITERATURA}

Los tumores gástricos secundarios constituyen una entidad clínica poco habitual, más aún si la localización del tumor primitivo es el riñón. Hasta la actualidad tan solo se han descrito 11 casos diagnosticados en vida.

Se presenta un caso clínico de una mujer que presentó una hemorragia digestiva alta secundaria a la presencia de una metástasis gástrica de carcinoma de células renales cuatro años después de la nefrectomía radical. Se realiza una revisión bibliográfica de los casos descritos hasta la fecha en pacientes vivos y se establece una hipótesis patogénica de acuerdo a las teóricas rutas de diseminación para los casos de localización metastática gástrica.

PALABRAS CLAVE: Adenocarcinoma renal. Metástasis gástrica. Patogenia.

\section{ABSTRACT \\ GASTRIC METASTASIS FROM RENAL CELL CARCINOMA. PATHOGENICAL HYPOTHESIS AND LITERATURE REVISION}

Secondary gastric tumours are very uncommon clinical entities and even more so when the site for the primary tumour is the kidney. Only 11 cases of life diagnosis have been described up to now.

Contribution of one case report: a female patient presenting with upper GI tract haemorrhage secondary to gastric metastasis from renal cell carcinoma four years after radical nephrectomy.

A literature review is made on the cases described up to date in living patients and a pathogenic hypothesis established based on the theoretical dissemination routes for the cases of gastric location of the metastasis.

KEY WORDS: Renal adenocarcinoma. Gastric metastasis. Pathogeny.

Losing os tumores gástricos metastáticos constituyen una patología excepcional, con una frecuencia en estudios de autopsias que oscila entre el $0,2 \%$ y el $0,7 \%$. En este sentido, las neoplasias primarias más frecuentes, son las de mama, bronquio y el melanoma ${ }^{1-3}$. El adenocarcinoma renal, posee un gran potencial metastático; aproximadamente un $30 \%$ de los pacientes se presentan al diagnóstico con metástasis y hasta un 50\% de los carcinomas renales inicialmente órgano-confinados, van a metastatizar en cualquier órgano de la economía ${ }^{4}$. El carcinoma de células renales con diseminación metastática a estómago y diagnosticado en vivo, se ha descrito en tan solo 11 casos $^{5-15}$. 
Generalmente se trata de metástasis metacrónicas que debutan con dolor abdominal inespecífico y hemorragia digestiva alta o baja. La endoscopia y ecoendoscopia oral, pone de manifiesto habitualmente, lesiones pequeñas de localización submucosa y con un aspecto típico en "volcán". La supervivencia descrita es variable, de acuerdo, sobre todo, a la presencia o no de enfermedad metastática en otras localizaciones, situación que condiciona la radicalidad o no del tratamiento.

Se aporta un nuevo caso de metástasis gástrica de adenocarcinoma renal y se revisan las características clínicas de los casos publicados hasta la fecha, aportando una descripción de las teóricas rutas de diseminación tumoral para las metástasis gástricas.

\section{CASO CLÍnICo}

Mujer de 61 años que acudió al Servicio de Urgencias de nuestro hospital por dolor epigástrico de un mes de evolución y esporádicamente deposiciones de características melénicas, asociado a astenia intensa.

Cuatro años antes, había sido sometida en otro centro hospitalario, a una nefrectomía radical izquierda por un proceso sólido en el riñón, cuyo resultado anatomopatológico puso de manifiesto la presencia de un adenocarcinoma renal de células claras, grado citológico II- III de Führman, que infiltraba la cápsula e invadía la vena renal: T3b NO MO, IIIa de Robson. Dos años después del diagnóstico inicial, fue sometida a una lobectomía superior del pulmón derecho por una metástasis solitaria por el mismo tumor renal y el último control oncológico, hacía un año, no había demostrado diseminación tumoral.

En la exploración física, destacaba una intensa palidez cutáneo-mucosa así como dolor a punta de dedo en epigastrio, sin defensa ni signos de irritación peritoneal; el tacto rectal reveló la presencia de melenas, y el lavado por sonda nasogástrica fue de aspecto en "posos de café".

Las exploraciones complementarias para el diagnóstico, revelaron en sangre periférica una hemoglobina de 5,9 y un hematocrito de 18; iones y estudio de coagulación dentro de los límites normales.

Se procedió a realizar una panendoscopia oral, que puso de manifiesto la presencia de una lesión de $6 \mathrm{~cm}$ de diámetro a nivel de la curvadura mayor de cuerpo gástrico, de aspecto polipoideo, con pedículo amplio y en cuya superficie se apreciaba una ulceración de la mucosa. El resto de la cavidad gástrica y la primera porción duodenal fueron de aspecto normal (Fig. 1). Se procedió a tomar una biopsia de la lesión.

Con el objetivo de definir mejor la lesión, se realizó una ecoendoscopia gástrica, en la que se apreció que la imagen anteriormente descrita,

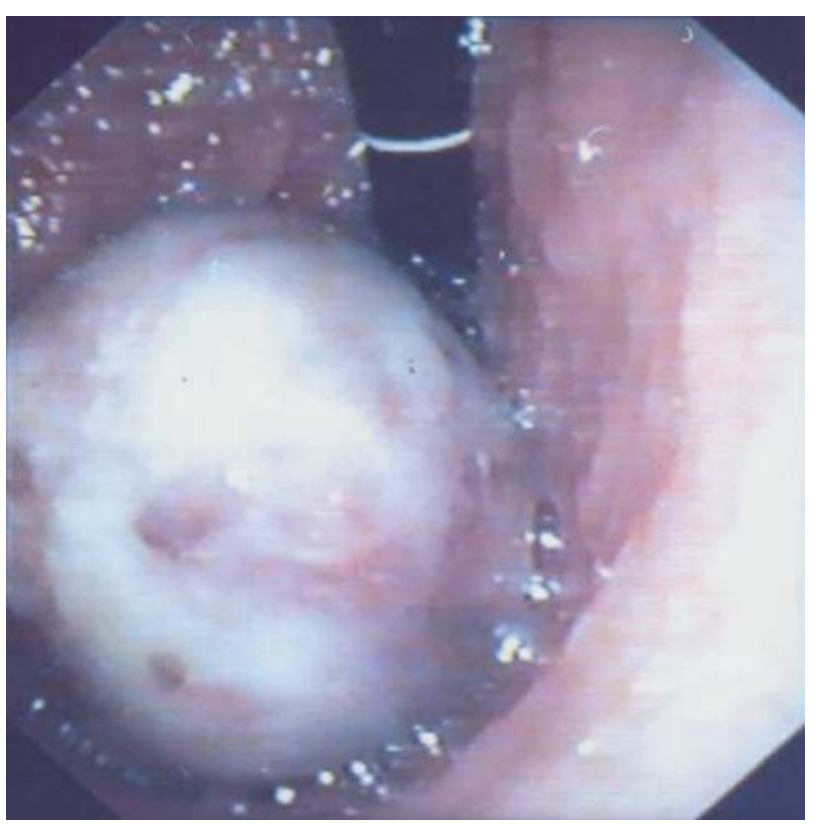

FIGURA 1. Gastroscopia. Lesión de $6 \mathrm{~cm}$, ulcerada, en curvatura mayor de cuerpo gástrico.

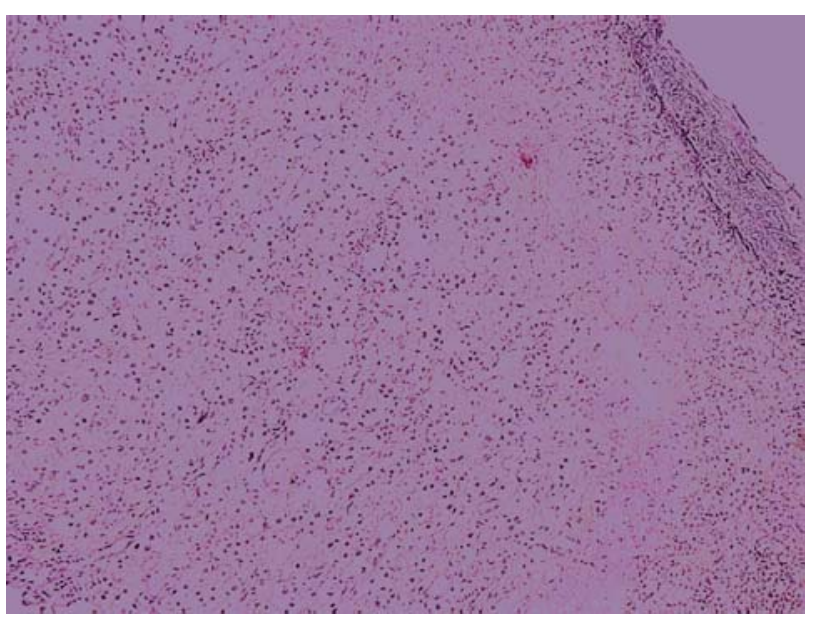

Figura 2: Mucosa gástrica extensamente infiltrada por una tumoración maligna de células claras (EMA+, CD34 -, Actina -) concordante con metástasis gástrica de carcinoma de células claras de origen renal. 
dependía de la capa muscular gástrica y se acompañaba de un engrosamiento tanto de la mucosa como de la submucosa.

El resultado histopatológico de la biopsia de la lesión, fue de metástasis de un carcinoma de células claras de riñón (Fig. 2).

A la vista del resultado histológico, se procedió a completar el estudio de extensión que puso de manifiesto la presencia de metástasis pulmonares bilaterales y adenopatías mediastínicas de tamaño patológico.

El episodio de hemorragia digestiva no se repitió en la semana siguiente y dado que nos encontrábamos ante una enfermedad diseminada, se optó por tratamiento paliativo. Seis meses después, no recidivó la hemorragia digestiva y la paciente se encontraba con enfermedad estable.

\section{DISCUSIÓN}

El carcinoma de células renales (CCR), desde el punto de vista biológico, posee un gran potencial metastásico, no sólo al diagnóstico, sino durante todo el curso evolutivo de la enfermedad. Entre sus peculiares características clínico-biológicas, destaca su capacidad para evadir los mecanismos de vigilancia del sistema inmune, situación que explica la aparición de metástasis en localizaciones no habituales como la descrita en este caso.

Los tumores gástricos secundarios o metastáticos, constituyen una entidad clínica no habitual, con una frecuencia estimada en estudios de autopsias entre el 0,2\% y el 0,7\%; en este sentido, las localizaciones neoplásicas primitivas más frecuentes, incluyen al cáncer de mama, broncopulmonar y al melanoma ${ }^{1-3}$. De un total de 68.560 autopsias $^{1-3}$, en 157 casos se detectaron tumores gástricos secundarios y en sólo 2 , el tumor primitivo fue de riñón.

En pacientes vivos, se han publicado 11 casos de metástasis de un CCR, cuyas características clínico-evolutivas se resumen en la Tabla $1^{5-15} \mathrm{y}$ en la que se ha incluido el presente caso clínico.

Se trataba de pacientes con una edad media al diagnóstico de 64 años (50-84 años), 7 hombres y 5 mujeres, que consultaron habitualmente por hematemesis y/o melenas; se les había practicado una nefrectomía previa por CCR, salvo en dos $\operatorname{casos}^{7,12}$ en los cuales el hallazgo de la metástasis gástrica y el tumor renal fue sincrónico. El tumor renal fue de localización izquierda en 8 casos y derecha en 3, y el estadio patológico fue variable. La mitad de los pacientes, presentaban metástasis en otras localizaciones (pulmón, pleura, cerebro e ileon) y en el 50\% restante se trataba de una metástasis gástrica solitaria. El tiempo medio transcurrido desde la nefrectomía hasta el diagnóstico de la metástasis fue de 7,5 años (0-24 años).

Endoscópicamente, se puede apreciar la presencia de lesiones polipoideas, pedunculadas o en placa, únicas o múltiples, generalmente de pequeño tamaño (en nuestro caso la más voluminosa: $6 \mathrm{~cm}$ ) y de aspecto submucoso; son sobreelevadas en su centro y con una ulceración en el vértice, apariencia que ha sido comparada a la forma de un "volcán"10. El diagnóstico diferencial endoscópico incluye al leiomioma ulcerado, carcinoide, linfoma, sarcoma de Kapossi, granuloma eosinófilo y páncreas heterotópico ${ }^{16}$.

Una metástasis en estómago de CCR en el seno de una enfermedad diseminada de localizaciones múltiples, se puede explicar según las rutas de diseminación clásica (hematógena a través del sistema venoso cava y linfática); sin embargo, la localización única tiene una difícil interpretación patogénica que podría explicarse por las rutas de diseminación no habituales: hematógena retrógrada venosa por las venas lumbares y linfohematógena a través del conducto torácico. $\mathrm{El}$ plexo lumbar es un sistema venoso de baja presión y avalvular ${ }^{17}$; entre sus conexiones se encuentra la vena gástrica izquierda (Fig. 3); un émbolo tumoral podría "viajar" retrógradamente a través de esta vía e implantarse en estómago. El conducto torácico es lugar de drenaje de los ganglios linfáticos para-aórticos entre otros, y se conecta con el sistema venoso en la vena subclavia izquierda; $\sin$ embargo, en el 40-60\% de los pacientes, el drenaje venoso puede ocurrir tanto en las venas lumbares como en el sistema ázigos ${ }^{18}$ (Fig. 3); a través de esta vía y tomando el mismo circuito anteriormente descrito, una metástasis en estómago puede aparecer en ausencia de otras localizaciones. Dada la localización anatómica del conducto torácico en el lado izquierdo, sería más probable que tumores renales izquierdos se diseminen por esta vía ( 8 casos) y que tumores derechos lo hagan a través de los plexos lumbares. 
Tabla 1

\begin{tabular}{|c|c|c|c|c|c|c|c|c|c|c|}
\hline Referencia & Edad & Sexo & Sintomas & $\begin{array}{l}\text { Apariencia } \\
\text { endoscópica }\end{array}$ & $\begin{array}{l}\text { Tiempo desde } \\
\text { nefrectomia } \\
\text { (años) }\end{array}$ & $\begin{array}{l}\text { Tumor } \\
\text { renal. } \\
\text { Localiz. }\end{array}$ & $\begin{array}{c}\text { Clasificación } \\
\text { TNM } \\
\text { (1997) }\end{array}$ & $\begin{array}{l}\text { Metástasis } \\
\text { adicional }\end{array}$ & $\begin{array}{l}\text { Tratamiento } \\
\text { metástasis } \\
\text { gástrica }\end{array}$ & $\begin{array}{l}\text { Supervi- } \\
\text { vencia }\end{array}$ \\
\hline $\begin{array}{l}\text { Nakamura }{ }^{6} \text { et al } \\
\text { (1984) }\end{array}$ & 65 & M & - & - & 9 & - & - & Ileon & - & - \\
\hline $\begin{array}{l}\text { Otowa }{ }^{7} \text { et al } \\
(1992)\end{array}$ & 61 & $\mathrm{~F}$ & Hematemesis & $\begin{array}{l}\text { Cuerpo } \\
\text { Múltiple }\end{array}$ & $\begin{array}{c}0 \\
\text { (sincrónica) }\end{array}$ & I & T2 N0 M1 & NO & $\begin{array}{l}\text { Nefrectomía + total } \\
\text { gastrectomía + distal } \\
\text { pancreatectomía + } \\
\text { esplenectomía }\end{array}$ & $\begin{array}{l}3 \mathrm{~m} \\
\text { vivo }\end{array}$ \\
\hline $\begin{array}{l}\text { Blake }^{8} \text { et al } \\
\text { (1995) }\end{array}$ & 63 & M & Hematemesis & Mucosa & 6 & $\mathrm{D}$ & - & Pulmón & $\begin{array}{c}\text { Paliativo } \\
\text { (embolización arteria } \\
\text { esplénica) }\end{array}$ & $\begin{array}{l}5 \mathrm{~m} \\
\text { vivo }\end{array}$ \\
\hline $\begin{array}{l}\text { Odori }^{9} \text { et al } \\
(1998)\end{array}$ & 59 & M & Asintomático & $\begin{array}{l}\text { Curvatura menor } \\
\text { Ulceración central }\end{array}$ & 4 & I & T2 N0 M0 & NO & $\begin{array}{l}\text { Gastrectomia } \\
\text { total }\end{array}$ & $\begin{array}{l}17 \mathrm{~m} \\
\text { vivo }\end{array}$ \\
\hline $\begin{array}{l}\text { Mascarenhas }{ }^{10} \text { et al } \\
(2001)\end{array}$ & 66 & M & $\begin{array}{l}\text { Hematemesis } \\
\text { Melena }\end{array}$ & $\begin{array}{l}\text { Curvatura mayor } \\
\text { Ulceración central } \\
2 \mathrm{~cm}\end{array}$ & 7 & I & - & $\begin{array}{l}\text { Pulmón } \\
\text { Pleura }\end{array}$ & $\begin{array}{l}\text { Gastrectomia } \\
\text { parcial }\end{array}$ & $\begin{array}{l}36 \mathrm{~m} \\
\text { exitus }\end{array}$ \\
\hline $\begin{array}{l}\text { Picchio }^{11} \text { et al } \\
(2000)\end{array}$ & 50 & $\mathrm{~F}$ & Melena & $\begin{array}{l}\text { Curvatura menor } \\
\text { Ulceración central } \\
1 \mathrm{~cm}\end{array}$ & 14 & I & T2 N0 M0 & NO & $\begin{array}{l}\text { Gastrectomia } \\
\text { subtotal }\end{array}$ & $\begin{array}{l}6 \mathrm{~m} \\
\text { vivo }\end{array}$ \\
\hline $\begin{array}{l}\text { Márquez }{ }^{12} \text { et al } \\
\text { (1992) }\end{array}$ & 67 & M & Melena & $\begin{array}{l}\text { Cuerpo } \\
\text { Ulceración central } \\
1,5 \mathrm{~cm}\end{array}$ & $\begin{array}{c}0 \\
\text { (sincrónica) }\end{array}$ & I & - & Pleura & Paliativo & $\begin{array}{l}14 \text { days } \\
\text { exitus }\end{array}$ \\
\hline $\begin{array}{l}\text { Ibáñez }{ }^{13} \text { et al } \\
\text { (1989) }\end{array}$ & 60 & $\mathrm{~F}$ & Melena & $\begin{array}{l}\text { Curvatura mayor } \\
\text { Ulceración }\end{array}$ & 2 & I & T3a N0 M0 & $\begin{array}{l}\text { Pulmón } \\
\text { Cerebro }\end{array}$ & Resección & $\begin{array}{c}2 \mathrm{~m} \\
\text { exitus }\end{array}$ \\
\hline $\begin{array}{l}\text { Bisesti }^{15} \text { et al } \\
(1984)\end{array}$ & 64 & M & $\begin{array}{l}\text { Dolor } \\
\text { torácico }\end{array}$ & $\begin{array}{l}\text { Antro } \\
\text { Ulceración } \\
2,5 \mathrm{~cm}\end{array}$ & 14 & $\mathrm{D}$ & - & NO & $\begin{array}{l}\text { Gastrectomía } \\
\text { subtotal }\end{array}$ & - \\
\hline $\begin{array}{l}\text { Suárez et al } \\
(2003)\end{array}$ & 61 & $\mathrm{~F}$ & $\begin{array}{c}\text { Melena } \\
\text { Epigastralgia }\end{array}$ & $\begin{array}{l}\text { Curvatura mayor } \\
\text { Ulceración central } \\
6 \mathrm{~cm}\end{array}$ & 4 & I & T3b N0 M0 & Pulmón & Paliativo & $\begin{array}{l}6 \mathrm{~m} \\
\text { vivo }\end{array}$ \\
\hline
\end{tabular}

Las lesiones metastáticas pueden quedar localizadas en la submucosa gástrica e ir creciendo lentamente hasta infiltrar la mucosa y ulcerarla ${ }^{9,10,14}$; esta situación podría explicar el amplio intervalo de tiempo desde la nefrectomía hasta su detección (hasta 24 años ${ }^{14}$ ).

El tratamiento de estas lesiones ha de ser necesariamente individualizado de acuerdo al estado general del paciente y sobre todo condicionado por la presencia o no de enfermedad diseminada múltiple. En términos generales, la cirugia radical (gastrectomía parcial/total) estaría indicada en aquellos casos de localización única ${ }^{5,7,9,11,15}$, si el estado general del paciente lo permite. Otras modalidades terapéuticas utilizadas, sobre todo en el contexto de una enfermedad diseminada múltiple y en pacientes de riesgo quirúrgico elevado, incluyen la embolización paliativa de la arteria esplénica ${ }^{8}$, la resección quirúrgica en cuña ${ }^{13}$, la electrocoagulación endoscópica (nuestro caso), así como la resección endoscópi$\mathrm{ca}^{9,11}$, todas ellas con fines paliativos y con el objetivo común de detener el sangrado digestivo. Asimismo es conocido el beneficio, en términos de supervivencia, en el tratamiento adyuvante del CCR metastástico mediante el uso de modificadores de la respuesta biológica (Interleukina- 2 e Interferon $\alpha$ ). 


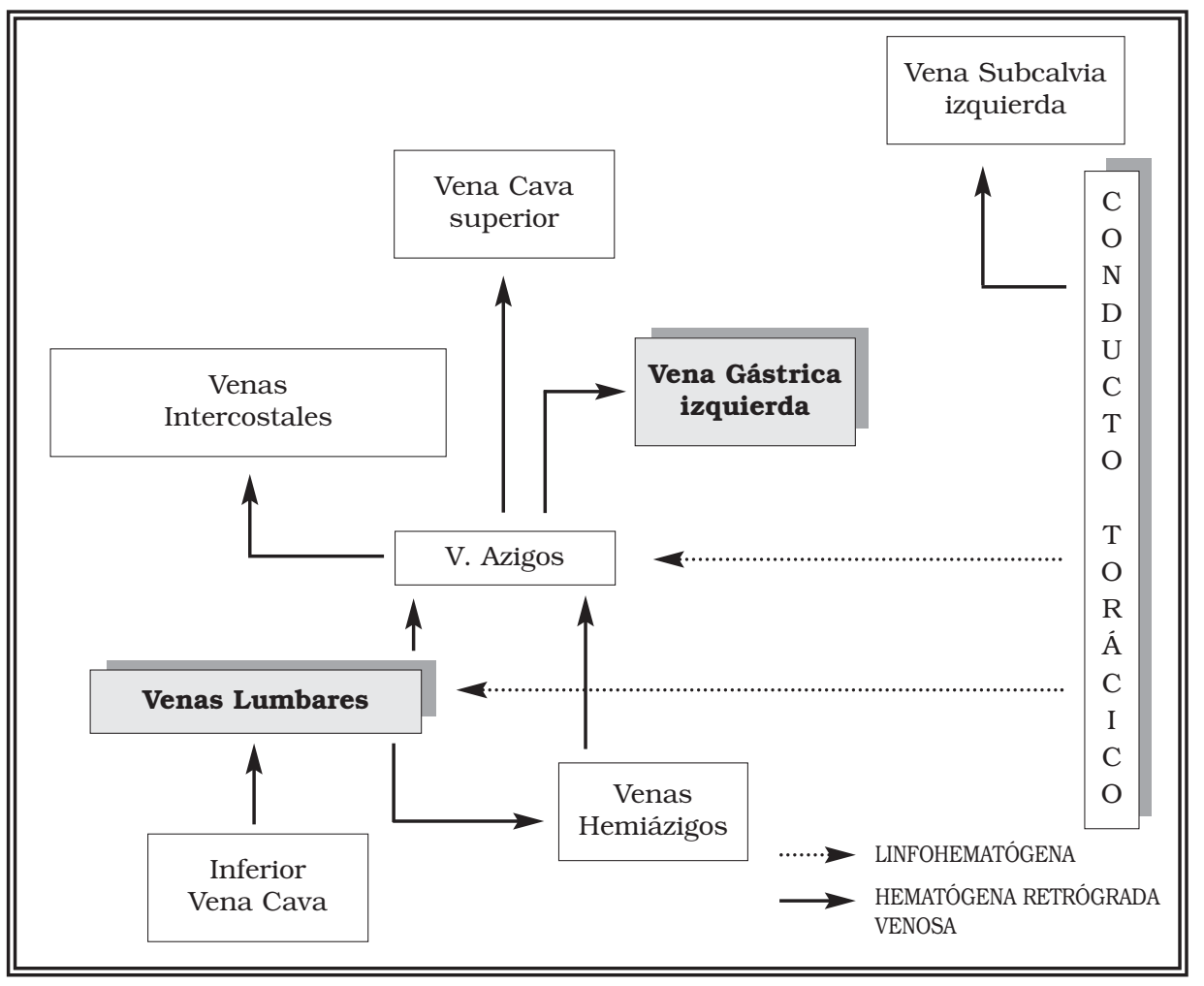

FIGURA 3. Teóricas rutas de diseminación del CCR a través del conducto torácico y por las venas lumbares.

\section{REFERENCIAS}

1. DAVIS GH, ZOLLINGER RW.: Metastatic melanoma of the stomach. Am J Surg 1960; 99: 94.

2. HIGGINS PM.: Pyloric obstruction due to a metastatic deposit from carcinoma of the bronchus. Canad J Surg 1962; 5: 438.

3. MING S.: Tumor of the esophagus and stomach. En: atlas of tumor pathology, $2^{\text {nd }}$ series, part 7 , Armed Forces Institute of Pathology, Bethesda, 1973: 253-255.

4. SAITOH H, NAKAYAMA M, NAKAMURA K, SAITOH T.: Distant metastasis of renal adenocarcinoma in nephrectomized cases. $J$ Urol 1982; 127: 1092.

5. SULLIVAN WG, CABOT EB, DONOHVE RE.: Metastatic renal cell carcinoma to stomach. Urology 1980; 15: 375-378.

6. NAKAMURA R, SHIMADA A, NAKAMURA K.: One case of intussusception due to intestinal metastasis of renal carcinoma. Jpn J Clin Surg 1984; 45: 1637-1640.

7. OTAWA T, MUTO I.: A case of synchronous gastric metastasis from renal cell carcinoma with the chief complaint of hematemesis. Jpn J Clin Surg 1992, 53: 1219-1222.

8. BLAKE MA, OWENS A, O`DONOGHUE DP.: Embolotherapy for massive upper gastrointestinal haemorrhage secondary to metastatic renal cell carcinoma: report of three cases. Gut 1995; 37: 835-837.

9. ODORI T, TSUBOI Y, KATOH K, YAMADA K, MORITA K, OHARA A, KUROIWA M, SAKAMOTO H, SAKATA T.: A solitary hematogenous metastasis to the gastric wall from renal cell carcinoma four years after radical nephrectomy. J Clin Gastroenterol 1998 mar; 26 (2): 153-154.

10. MASCARENHAS B, KONETY B, RUBIN JT.: Recurrent metastatic renal cell carcinoma presenting as a bleeding gastric ulcer after a complete response to high-dose interleukin-2 treatment. Urology 2001 jan; 57 (1): 168.
11. PICCHIO M, PAIOLETTI A, SANTINI E, IACOPONI S, CORDAHI M.: Gastric metastasis from renal cell carcinoma fourteen years after radical nephrectomy. Acta Chir Belg 2000 sep-oct; 100 (5): 228-230.

12. MÁRQUEZ JL, HERRERA JM, HERRERA J, CABALLERO M, NARVAEZ I, PASCASIO JM et al.: Gastric metastasis of renal cell adenocarcinoma. Rev Esp Enferm Dig 1992 feb; 81 (2): 129-130.

13. IBÁÑEZ J, JIMÉNEZ CE, OTEO JA, COBO F, SARA MJ, GARCÍA $M$ et al.: Metástasis gástrica de adenocarcinoma renal. Presentación de un caso clínico y revisión de la literatura. Rev Esp Enf Ap Digest 1989; 76: 259-261.

14. COSME A, ORIVE V, ALZATE LF, TORRADO J, ARENAL JI.: Metástasis gástrica de un hipernefroma. Gastroenterol y Hepatol 1984; 7: 400-401.

15. BISESTI V, PARRELLA E, CATALDI C, RIZZO R, ONUFRIO A.: Ser di un raro caso di metastasi gastrica di adenocarcinoma renale. Osp Ital Pediatr 1984; 19: 609-620.

16. DUTTA SK, COSTA BS.: Umbilicated gastric polyposis. Am J Gastroent 1979; 71: 598-600.

17. BATSON VO.: The function of the vertebral vein and their role in the spread of metastases. Ann Surg 1940; 112: 138-149.

18. MALTHANER RA, MCKNEALLY MF.: Anatomy of the thoracic duct and chylothorax. En: Griffith Pearson F, Deslauriers J, Ginsberg R, Hiebert C, McKneally M and Urschel H. Thoracic Surgery. Ed. Churchill Livingstone, New York. Tomo 1: 1069-1072.

Dr. C. Suárez Fonseca

Servicio de Urología. Hospital Univ. Puerta de Hierro San Martín de Porres, 4

28035 Madrid

(Trabajo recibido el 25 septiembre de 2003) 